\title{
MORPHOLOGICAL MODELLING OF THE RESPONSE TO A SHIPWRECK - A CASE STUDY AT CAPE TOWN
}

\author{
Sten Esbjørn Kristensen ${ }^{1}$, Rolf Deigaard ${ }^{2}$, Nils Drønen ${ }^{2}$, Jørgen Fredsoe ${ }^{1}$, Stephen Luger $^{3}$
}

\begin{abstract}
A simulation of the morphological development and degrade of a salient behind a shipwreck located north of Cape Town, South Africa is presented. The morphological model is based on a hybrid morphological model concept which combines a 2D coastal model for calculating sediment transport with a simplified 1D morphological evolution model for the coastline. The model concept is applied to the case study in order to show how the modelling concept may be applied to real coastlines with general bathymetric features. The results show that the model captures the overall morphological response fairly well without the need for extensive calibration which is often required by traditional $2 \mathrm{D}$ morphological models. This is attributed by the authors to the fact that the sediment transport description is based on a process based model that captures the most important features, while neglecting the often challenging description of the cross-shore sediment transport.
\end{abstract}

Keywords: Hybrid morphological model; Breakwater; Shoreline modeling; Seli 1

\section{INTRODUCTION}

Shoreline evolution is affected by gradients in the littoral drift. Accurate calculation of the littoral drift along the shoreline is therefore important in order to establish a morphological model which can give reasonable predictions of the shoreline evolution. Several types of models for calculating the littoral drift along a coast have been developed, some of these are empirical methods based primarily on the angle between the approaching waves and the the shoreline normal (e.g. CERC) and other models are based on a mix between processes and empirical relations (e.g. LITLINE by DHI and Unibest-CL+ by Deltares). The process based shoreline models typically solve the wave action equation for calculating the wave height distribution over an alongshore uniform discrete coastal profile and use derived radiation stress gradients to force a flow model which is based on the alongshore uniform depth-integrated momentum equation and continuity equation. Application of process based models for coastline evolution is thus possible because the area over which the models are solved on is reduced compared to a full 2D solution as is done in area models such as MIKE21 FM and Delft 3D. Effects from coastal structures on the littoral drift need however to be incorporated by use of additional models, since these effects are not included in the 1D solution due to the alongshore uniform assumption.

Process based area models have no need for incorporating additional models for effects of coastal structures since effects of alongshore non-uniformity are inherent in this type of model. An accurate calculation of the effect of coastal structures on the littoral transport may therefore be obtained by extracting the transport signal from the solution of a coastal area model. The extracted transport signals may be used as basis of a 1D morphological model which can be used to evolve the shoreline in time by shifting the entire coastal profile onshore/offshore thus reflecting erosion/accretion respectively (see figure 1 for an illustration of the concept). We will call this concept a hybrid morphological model because it couples a coastal area model for waves, flow and sediment transport with a 1D morphological shoreline model.

The hybrid morphological model is the next obvious step from the existing state-of-the-art shoreline models towards the full 2D coupled models. Development of hybrid morphological model concept is motivated by previous observations which show that 2D coastal models presently predict reasonable alongshore variations of the littoral drift during the initial phase of a full 2D morphological simulation. Maintaining a reasonable variation of the littoral drift is however complicated after some time unless the 2D coastal model is carefully calibrated such that the form of the coastal profile is maintained.

The hybrid morphological model concept allows the 2D coastal model to quantify the alongshore erosion/deposition field while the 1D morphological model defines the sediment distribution within the coastal profile. Introduction of a simplification to the morphological development of the bathymetry removes thus the requirement for careful calibration of cross-shore processes, thereby in principle making the model easier to use while obtaining accurate predictions of the shoreline evolution.

\footnotetext{
${ }^{1}$ Department of Mechanical Engineering, Technical University of Denmark, DK-2800 Kgs. Lyngby, Denmark

${ }^{2}$ DHI, Agern Allé 5, DK-2970 Hørsholm, Denmark

${ }^{3}$ Prestedge Retief Dresner Wijnberg, Marina Centre, West Quay Rd, Cape Town, South Africa
} 


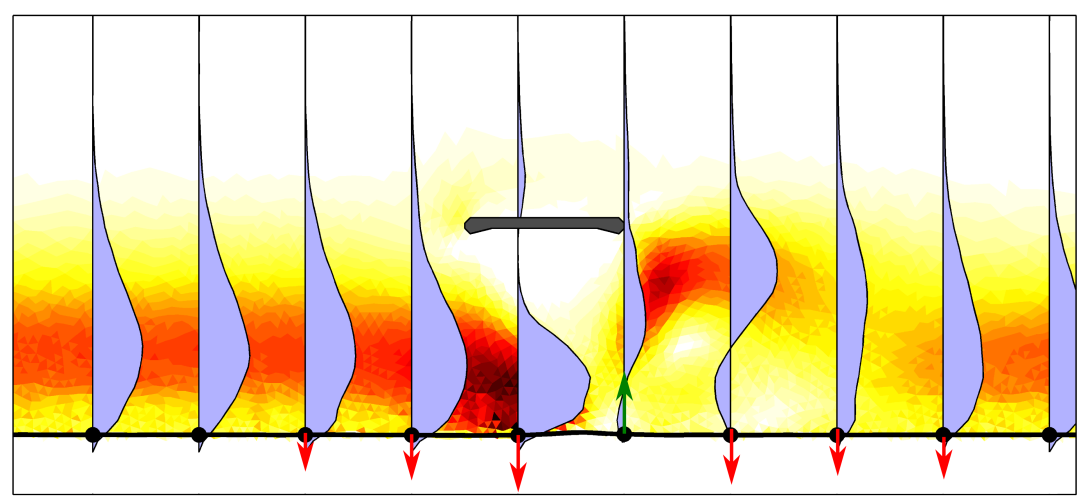

Figure 1: Illustration of the hybrid morphological modelling concept. A coastal area model is used to calculate a sediment transport field based on the existing shoreline. The transport is extracted along profiles, and alongshore differences in transport give rise to a change in shoreline position as indicated by the red and green arrows. The 2D coastal model and the 1D shoreline model are coupled to form a hybrid morphological model.

\section{Previous application of the hybrid model concept}

The hybrid morphological concept is first applied by Hansen et al. (2004) where it is used to simulate bar dynamics with formation of rip channels and interaction with a river mouth. The model was shown to predict a dynamic equilibrium where the bar-rip system migrates along the shoreline. Kærgaard (2011) uses the hybrid morphological concept to predict evolution of shoreline undulations and sandy spits for shorelines subject to very oblique wave incidence. In the study of Kærgaard (2011) special attention is given to a moving grid which enhances the models computational efficiency while including the effect of curvature on the result. A case study from the West Coast of Namibia, Africa shows that the model predictions are reasonably accurate in terms of measured spit dimensions.

Various adaptations of the hybrid morphological model to different coastal problems involving both hard and soft shoreline management schemes are presented in Kristensen et al. (2010). The study shows both examples of how the concept may be used to quantify morphological development and how variation in the number of degrees of freedom in the morphological model will affect the end result. The strength of the hybrid morphological model concept is demonstrated in Drønen et al. (2011) where the model concept is applied to offshore breakwaters. The morphological model is first validated against the gradual formation of a salient behind an offshore breakwater. It is then used to simulate shoreline evolution behind a new future breakwater configuration. In the study they show that the model concept is robust and reliable.

Additional validation of the model concept is however still required and this paper presents a recent addition to this by showing the adaptation of the model to a ship-wreck located off the beach of Table View approximately $10 \mathrm{~km}$ north of Cape Town, South Africa. The model concept is applied with a minimum of calibration but is still capable of obtaining reasonable agreement with shoreline response seen on aerial photos.

\section{NUMERICAL MODEL}

The hybrid morphological model is implemented in a framework inside Matlab. The model calls the coastal area model MIKE21 FM from DHI. The coastal area model consists of a spectral wave model for transformation of waves, a non-linear depth integrated flow model and a process based sediment transport model STP which calculates the transport given the local wave and flow characteristics.

The 1D morphological model updates the shoreline position relative to a linear baseline and is based on gradients in the littoral drift following the 1D continuity equation:

$$
\frac{\partial s_{0}}{\partial t}=\frac{-1}{1-n} \frac{1}{h_{\mathrm{act}}} \frac{\partial Q_{l}}{\partial r}
$$


where $s_{0}$ is the shoreline position and $r$ is an alongshore coordinate. $n$ is the porosity which is included because the sediment transport model STP calculates transport in solid volume. $h_{\text {act }}$ is the height of the active profile.

The littoral drift $Q_{l}$ is calculated by numerical integration of the longshore transport extracted along coastal profiles from the output of the coastal area model. The alongshore gradient is evaluated by use of a first order upwind finite volume scheme and an explicit Euler scheme is used for time integration. The combination of the first order upwind scheme for spatial gradients and the explicit Euler scheme for time integration leads to a robust and dissipative solver, which is favourable in the morphological simulations.

\section{CASE STUDY - SELI 1, CAPE TOWN \\ A brief history of the shipwreck}

The grounded ship was a Turkish bulk carrier called Seli 1 and it ran aground on September 7th 2009 during a storm. The ship is $177 \mathrm{~m}$ long and is located approximately $500 \mathrm{~m}$ from the shoreline at a water depth of $9 \mathrm{~m}$ (this is based on a survey of the area from 2006). The Seli 1 was abandoned by the owners when it was realised that it could not be re-floated. Although the ships cargo was removed within 2009 due to the risk of pollution, the wreck itself remained on the ground because the structure of the ship was too damaged to risk a re-floatation. Work on dismantling the ship started therefore in 2010. In April 2011 only the hull remained and it is expected to be removed by the winter storms such that the wreck is removed completely at the end of 2012.

\section{The site - Table Bay}

The wreck is located in Table Bay which is enclosed by two rocky headlands; Mouille Point to the south and Bloubergstrand to the north. The two headlands are separated by a long curved beach which is supplied with a limited amount of sediment from the Diep river, Harris (1993). The beaches in Table Bay are sheltered by the headland to the south and by Robben island which is located $8 \mathrm{~km}$ west of Blouberg strand. Figure 2 shows an overview of Table Bay and a close-up of the area where the ship is stranded.

The waves in the area are composed of locally generated wind waves and the swell waves generated by distant storm centres in the southern latitudes Harris (1993). The combination of the swell waves from the south-west and the headland to the south means that there tends to be an increase in breaking wave height along Table Bay going from south to north. This results in a sorting of the sediment with fine sediment $d_{50}=0.15 \mathrm{~mm}$ in the south to $d_{50}=0.4 \mathrm{~mm}$ in the north measured at the mean water level.

There is a steady net littoral drift towards the north although winter storms (May-September) cause a significant increase in the gross-transport. The northward net transport leads to a general erosional trend in the southern part of the bay, although the bay as a whole is stable.

\section{The beach at Table View}

Extra attention is given to the beach at Table View because the Seli 1 is stranded at this location. The aerial photo of the beach shown in figure 2 shows the condition of the beach (in 2009) prior to the grounding of the Seli 1 together with the average shoreline which is based on photos from years 20002002,2004-2006,2009. The accuracy of the average shoreline is not more than say $20 \mathrm{~m}$ since processes from tides, wind setup, swash and wave setup complicate detection of the shoreline from aerial photos. The average shoreline shows that it tends to be s-shaped thus the beach north of the wreck is more narrow than the beach south of the wreck. The shoreline variability in the aerial photos does not suggest an erosive or depositional trend in the area, and the shoreline is therefore expected to be in equilibrium with the wave climate prior to the grounding of the Seli 1, albeit some periodic variability due to bar-rip migration and seasonal shift in transport direction may exist.

\section{MODEL SETUP \\ Wave climate}

A two year record of the wave climate approximately $50 \mathrm{~km}$ West-South-West of the Seli 1 is used to generate an annual wave climate. The wave climate is a hindcast record provided by the National Centers of Environmental Prediction (NCEP) and includes significant wave height, peak wave period, mean wave direction, wind speed and direction at 3-hourly intervals. The offshore wave and wind climates are shown in figure 3 as a wave and a wind rose respectively. The wave rose is dominated by waves from the south-west which are swell waves with wave periods ranging from $9 \mathrm{~s}$ to $18 \mathrm{~s}$. Waves generated locally are primarily 


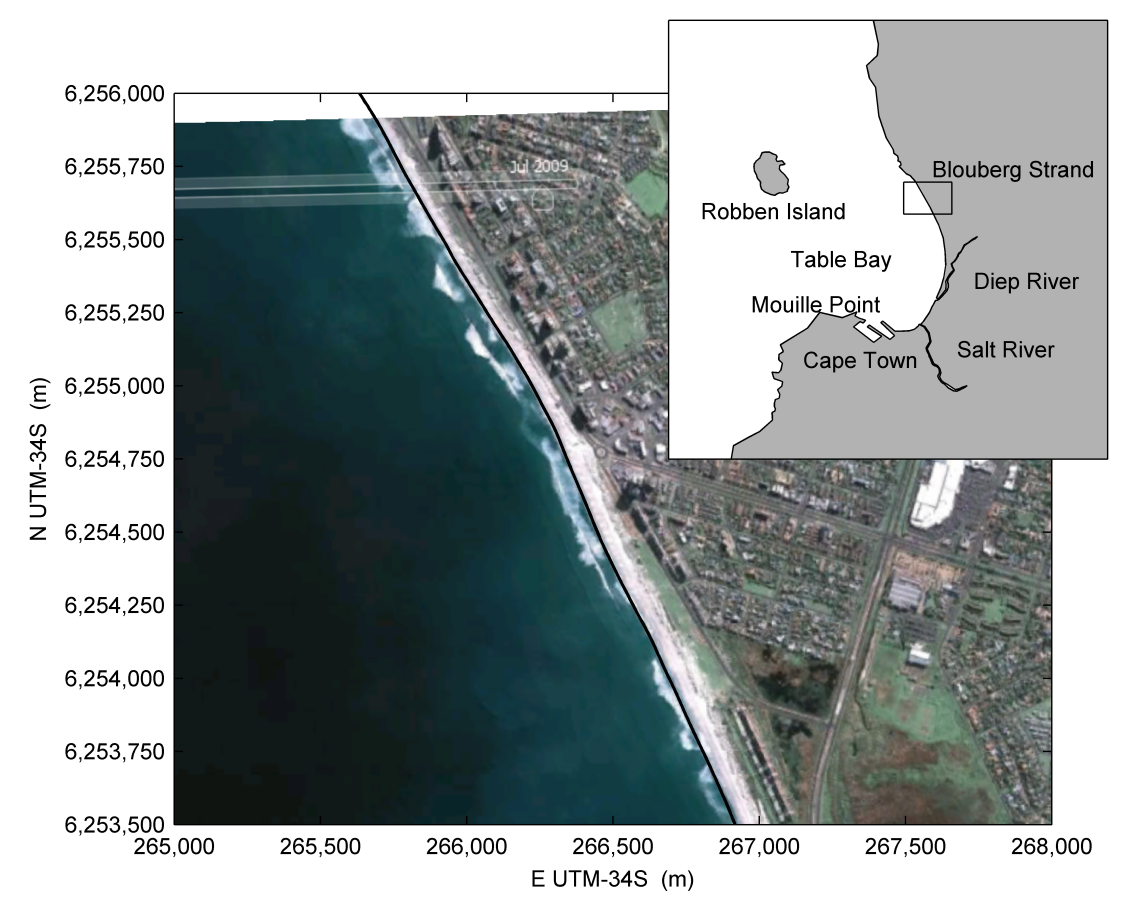

Figure 2: Overview of Table Bay. The average shoreline in the area where the Seli 1 is stranded is shown in the aerial photo supplied by Google Earth. There tends to be a local change in shoreline orientation in this area.

from the south-east and directed away from Table Bay. The wave period of the locally generated waves extends down to about $4 \mathrm{~s}$.
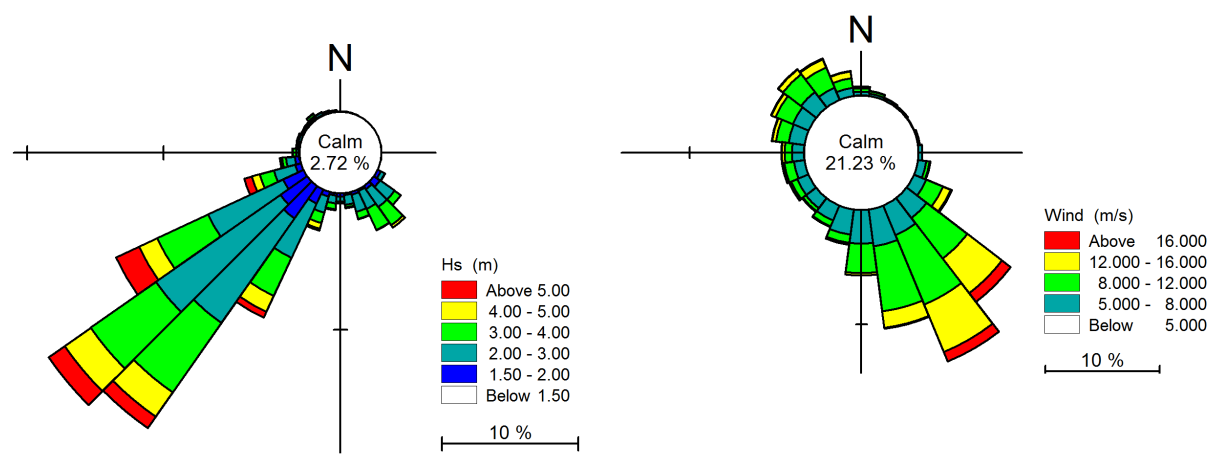

Figure 3: Diagrams of the wave (left) and wind (right) records from NCEP. The parameters are extracted at $\mathbf{E} 18^{\circ} \mathbf{S} 34^{\circ}$.

The seasonal variability of the wave climate is illustrated in figure 4 in terms of monthly averages and standard deviations. The figure shows that there tends to be slightly larger waves during the winter months (May-September). The increase in monthly standard deviation of the wave height $\left(\sigma_{H}\right)$ during the winter indicates that the storms are primarily located in this period. The mean wave direction is turned approximately $15 \mathrm{deg}$ counter clock-wise during the spring months in response to the waves being locally generated rather than being dominated by swell waves. This may also be seen by the sudden increase in directional variability for this period which is attributed to a shift towards wind generated waves rather than the unidirectional swell waves. The seasonal variability is not taken into account in the morphological simulations. 

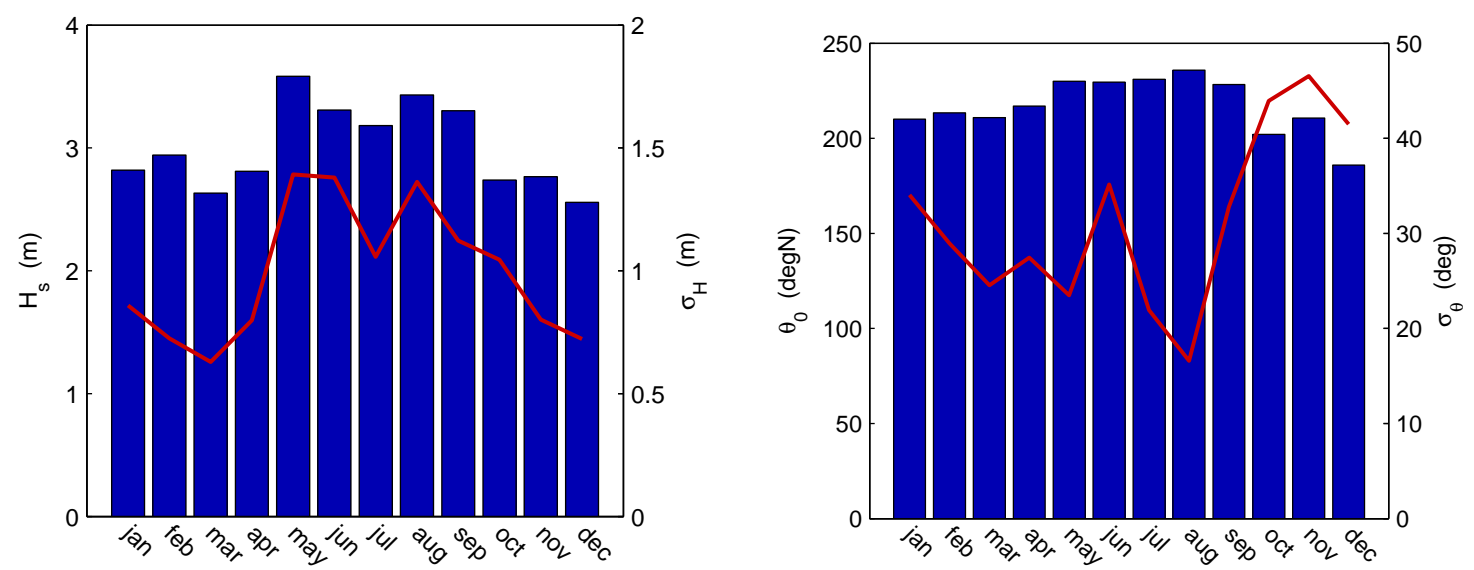

Figure 4: Seasonal variability of the offshore wave climate. Bar plots show monthly averages while the red curves are the monthly standard deviations.

Wave transformationThe recorded wave climate is condensed into a schematic wave and wind climate which can then be used to transform waves from an offshore location to a near-shore location inside Table Bay. The schematic wave climate is constructed by dividing the offshore wave climate into bins of similar wave direction and wave height. The wave height bins are equidistantly spaced by $0.5 \mathrm{~m}$. The bins for wave direction are spaced by $5 \mathrm{deg}$ for waves from south-west and west and $25 \mathrm{deg}$ for wave from the north-west. The annual duration of each wave class is determined and the schematic wave climate is constructed from the class mean values of the binned wave climate. The wave climate used in the morphological simulations consists of 103 wave events with durations ranging from $0.1 \%$ (9h) to $3.85 \%$ (14 days). This wave climate contains $80 \%$ of the full time series. Figure 5 shows the wave rose of the binned wave climate. The wave rose is similar to the wave rose of the raw offshore climate shown in figure 3 except for the exclusion of wave events with offshore propagating waves.

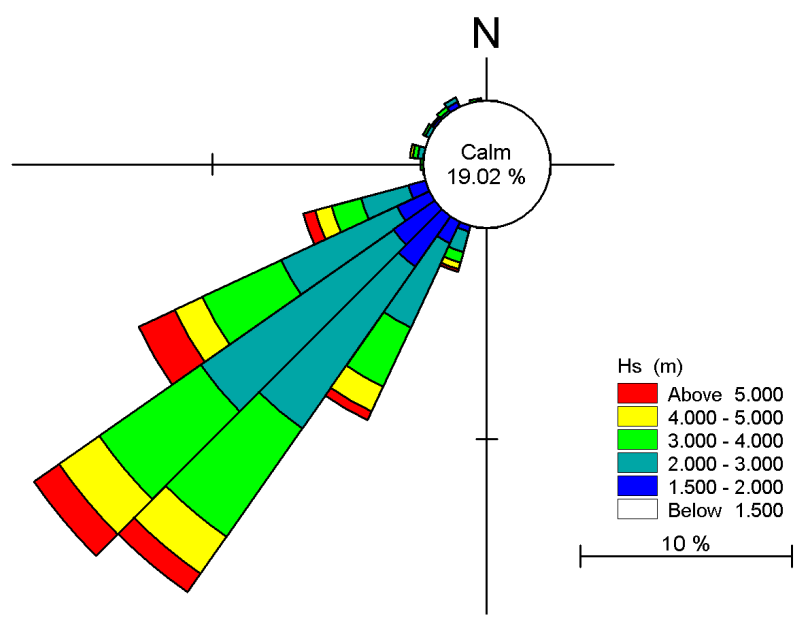

Figure 5: Wave rose of the binned wave climate. The wave climate consists of 103 events and contains events corresponding to $80 \%$ of the duration of a year.

Each wave event in the binned wave climate is associated with a class mean wind speed and wind direction. The class mean wind characteristics are constructed as simple averages of the wind speed and direction occurring concurrently with wave climates falling inside a specific wave bin. This simple method does lead to somewhat arbitrary forcing conditions when the climate is dominated by swell waves but it is nonetheless used because a better cross-correlation of the wind and wave climate would significantly 
increase the number of wave events thus reducing the efficiency of the model.

The schematic offshore wave climate is transformed into Table Bay by use of a full spectral wave model by DHI: MIKE21 SW. The model is run without feedback from hydrodynamics and each wave event is treated as a quasi-steady sea-state. The model is run with default/recommended settings for coastal application and no calibration is performed in this step. Figure 6 shows the bathymetry on which the offshore wave climate is transformed into Table Bay. The limits of the local domain used in the morphological simulations (described in the following section) is indicated by a black polygon. The transformed wave climate is indicated by the three wave roses along the offshore extent of the local domain. Comparing this figure with the wave rose of the schematic offshore wave climate in figure 5 shows clearly how the spreading of the wave climate inside Table Bay is reduced considerably due to refraction and due to sheltering from Robben island and the headland west of Cape Town. Furthermore; going from the southern part of the Bay towards north, the wave height tends to increase and the average wave direction turns anti clock-wise. The shoreline inside Table Bay is therefore oriented more or less perpendicular to the transformed wave climate thus suggesting that the net littoral drift is fairly small. This agrees well with the previously stated observations of the bay.

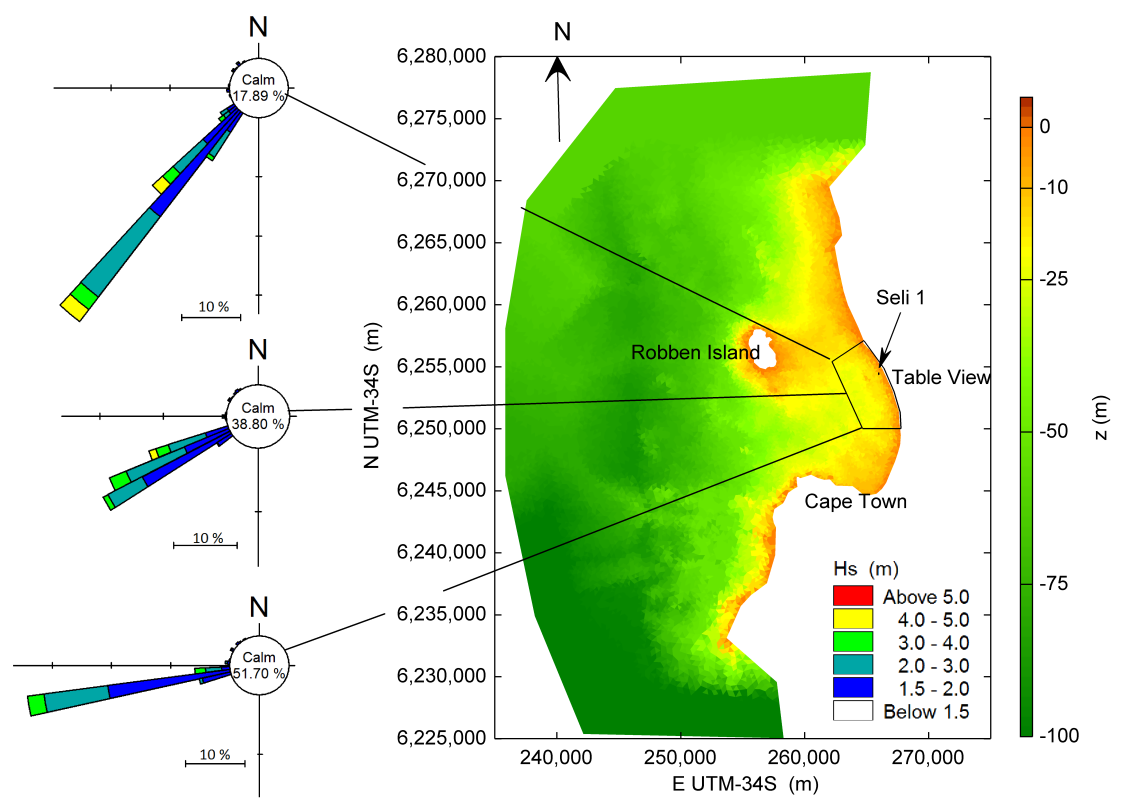

Figure 6: Global bathymetry used to transform the offshore wave climate into Table Bay. The result of the wave transformation is shown in terms of the wave roses. The black polygon indicates the extent of the local domain in which morphological simulations are performed. Vertical datum is given in meter relative to MSL.

\section{Domain for morphological simulations}

The morphological simulations are performed on a local domain. The local domain spans $7 \mathrm{~km}$ along the shoreline of Table Bay and extends $3 \mathrm{~km}$ into the bay. The domain is resolved by a fine $7-15 \mathrm{~m}$ triangular mesh in the near-shore area and a coarse triangular grid in the rest of the domain. The local domain is composed of an inactive part which covers bed levels below the depth of closure and an active part which is defined in terms of a parametric power profile which is added onto the inactive part, see figure 7. The active power profile is given by:

$$
z=z_{0}-A\left(s-s_{0}\right)^{m}
$$

where $z_{0}$ is the berm level, $s_{0}$ is the cross-shore position of the berm and $A, m$ are profile parameters. The active and the inactive part are combined to form the $2 \mathrm{D}$ bathymetry on which wave, current and sediment transport fields are calculated by the coastal area model.

The bathymetry of the inactive part is determined from a local survey of the area from 2006 which 


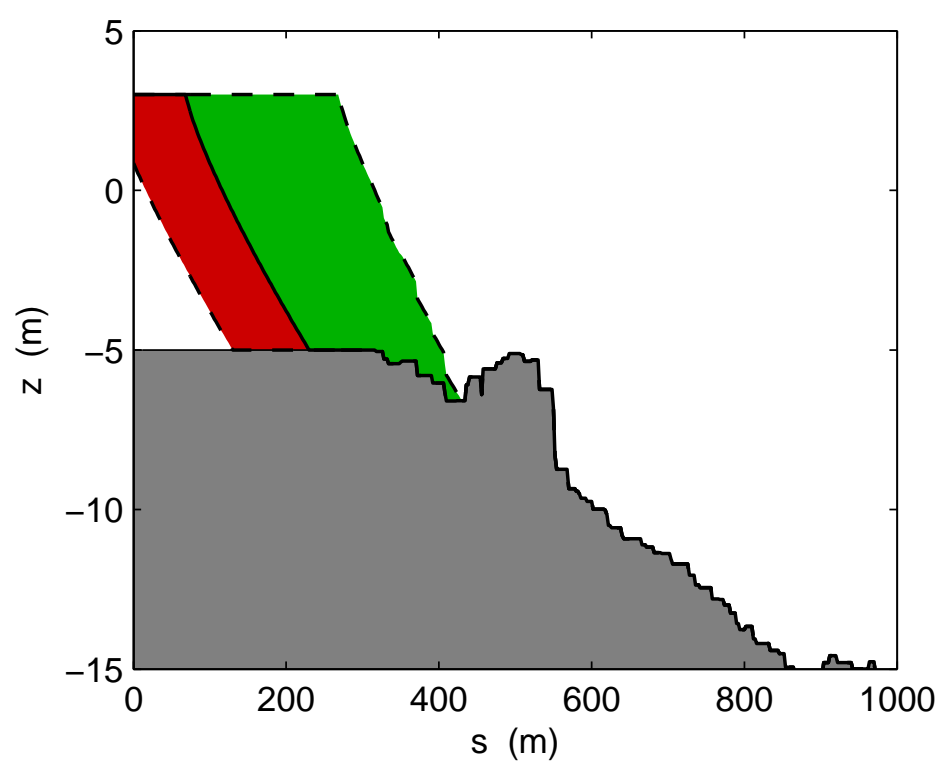

Figure 7: The coastal profile is composed on an inactive part (grey area) and an active part which responds to erosion/deposition by moving onshore or offshore respectively (red and green areas).

prior to interpolation onto the mesh is smoothed while retaining overall features of the measurement. The form of the active profile is chosen to be constant alongshore and is based on profiles extracted along the area and displaced towards a common origin. The profile parameters $A=0.9$ and $m=0.4$ are calculated as a best fit (see figure 8) to the entire dataset given a berm height $z_{0}=3 \mathrm{~m}$ and a closure depth $z_{c l}=-5 \mathrm{~m}$. This closure depth is chosen because the survey from the area shows that the coastal profiles are generally composed of a steep upper shoreface which flattens at around $z=-5 \mathrm{~m}$ followed by a lower shoreface with a mildly steep bed level gradient.

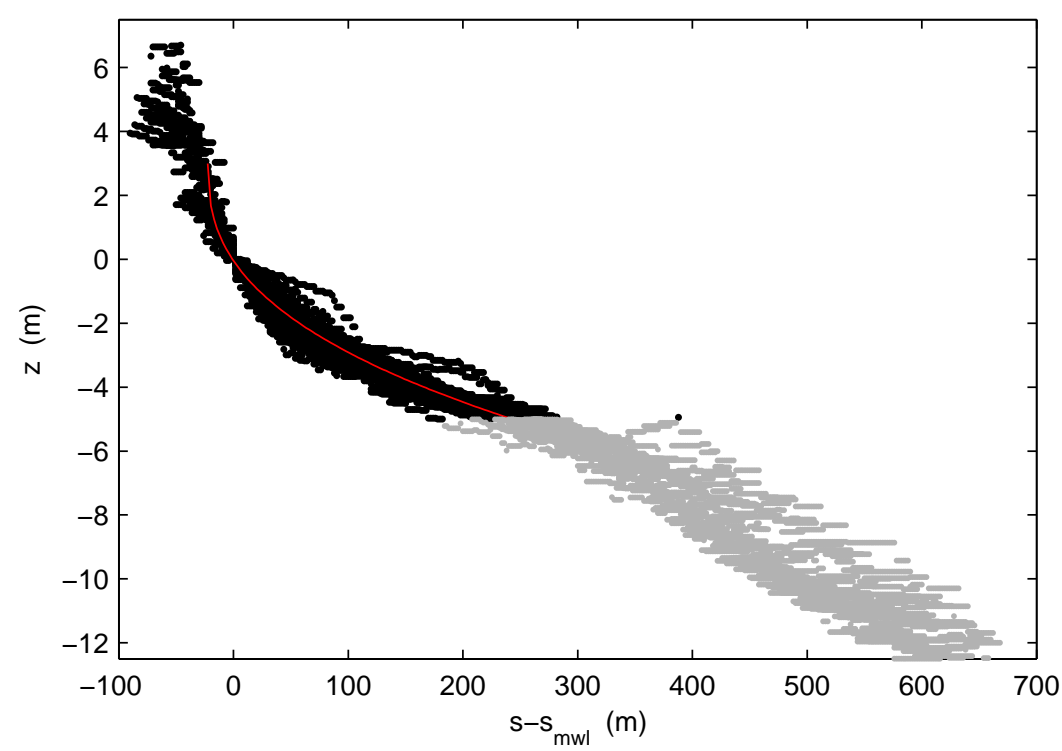

Figure 8: Comparison of the active profile against profiles generated from a field survey from 2006. The profile parameters of the active profile $(A$ and $m$ ) are chosen as the best fit to the extracted data. 


\section{MORPHOLOGICAL SIMULATIONS}

\section{Baseline - conditions prior to grounding of Seli 1}

The morphological model is set up to simulate shoreline evolution of the beach at Table View without the presence of the shipwreck in order to ensure that the transformed wave field is reasonable. The initial shoreline is determined from an aerial photo taken in 2009 a month prior to grounding of the ship, this shoreline is very similar to the average shoreline shown in figure 2.

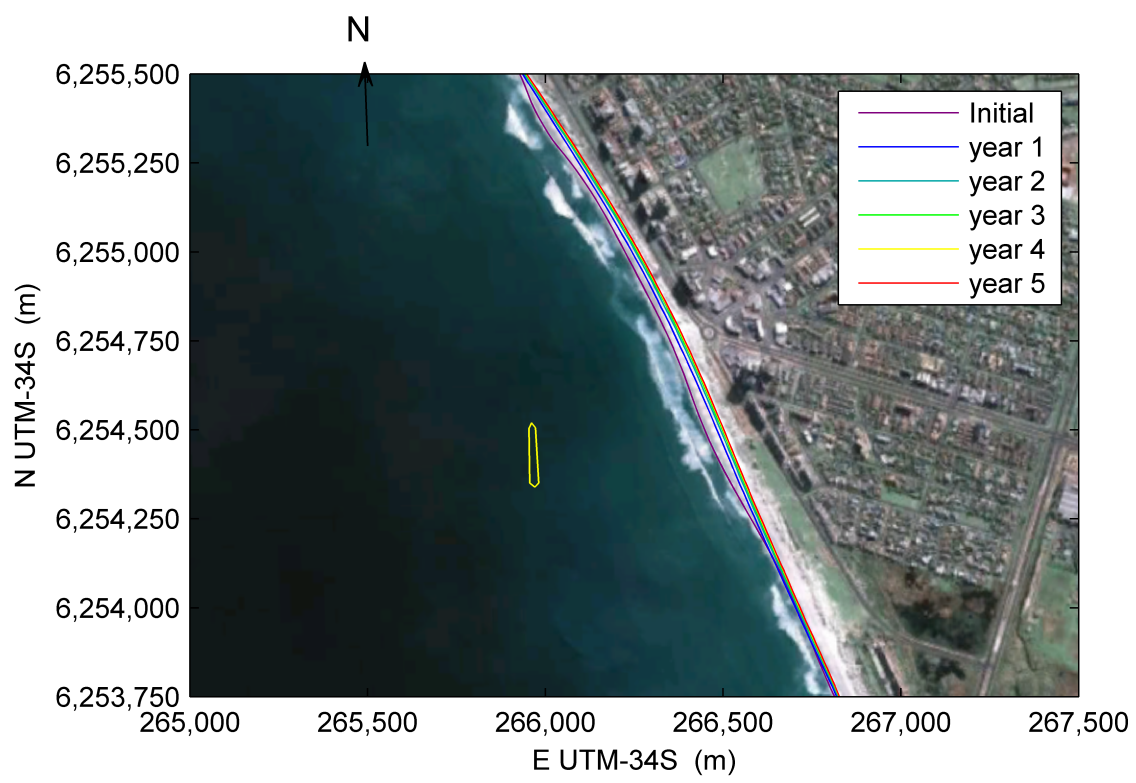

Figure 9: Simulated shoreline for baseline conditions (situation prior to grounding of the Seli 1). The model tends to overestimate erosion of the shoreline but reaches an equilibrium within 5 years of simulation.

The morphological model responds rapidly to the initial shoreline which is not in equilibrium with the wave forcing, but reaches an equilibrium within 5 years. The most pronounced feature of the morphological response is a removal of undulations on the initial shoreline and erosion of the beach in the area north of the future location of the shipwreck, see figure 9. As a matter of interest, this simulation shows also that the morphological model predicts a short transition from one shoreline orientation to another at the same position as is seen on the aerial photos. Simulations where the direction of the wave climate and the features of the inactive bathymetry are changed suggest that this sudden change in shoreline orientation is closely related to a shoal located at a water depth of $10-13 \mathrm{~m}$ roughly $1 \mathrm{~km}$ south-west of the future position of the wreck.

\section{Morphological response to shipwreck}

The impact of the shipwreck on the shoreline is determined by adding the shipwreck to the computational domain. The presence of the wreck causes sheltering from the approaching waves as would be the case from an offshore breakwater. The impact of the shipwreck on the littoral drift causes a salient to form as shown in figure 10. The figure compares the simulated shoreline against an aerial photo taken from the area a year after the grounding of Seli 1. The comparison shows that the morphological model gives a reasonable estimate of the salient amplitude and width, although the alongshore position of the salient tends to be located slightly too far to the south.

The position of the salient is fairly stable in the simulation due to the random permutation of the wave climate which therefore suppresses salient movement due to long periods with wave attack from a certain direction. Tests where the shoreline shown in figure 10 is used as initial condition and subject to constant waves from north and south show that the salient tends to move downstream, approximately $50 \mathrm{~m}$ and that the salient amplitude also decreases slightly. The salient response to the constant wave climate is in both cases approximately 2 months which makes it probable that seasonal variation will allow the salient some 


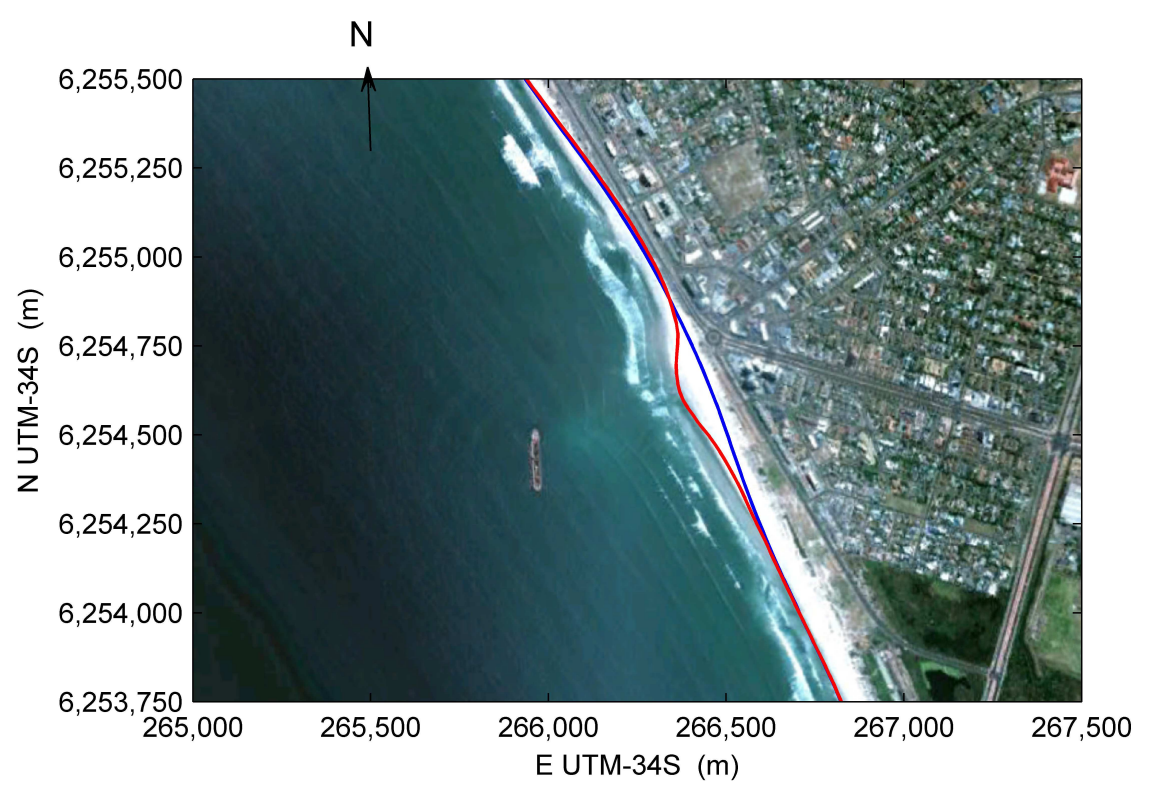

Figure 10: Planview of the simulated formation of a salient in the shadow zone behind Seli 1. Red curve: Equilibrium position. Blue curve: Initial condition.

activity. The variability in salient position is however too weak to describe the discrepancies seen in figure 10 .

\section{Morphological response to removal of shipwreck}

Removal of the shipwreck has been simulated with the morphological model showing that the salient disappears within a year. Aerial photos from 2011 show that the ship is broken into several pieces thus allowing an increase in penetration of wave energy into the shadow zone. The salient is at this point no longer easily identifiable. The predicted rapid disappearance of the salient seems therefore most likely.

\section{CONCLUSION}

Process based area models for coastal sediment transport are generally well suited for predicting the longshore transport and it's distribution across the profile. Their prediction of the cross-shore transport is however rarely sufficiently accurate to simulate the long term evolution of the coastal profile. The hybrid morphological model uses therefore only the the longshore transport variation for calculating evolution of the shoreline. This leads to a robust morphological model which can be applied with a fair amount of confidence to coastline evolution involving offshore breakwaters. This is illustrated by the case study presented in this paper and by the study presented in Drønen et al. (2011).

\section{ACKNOWLEDGEMENTS}

The first author has been supported by a grant from the Danish Agency for Science Technology and Innovation and by a grant from Otto Mønsteds Fond. This work has been partly supported by the Danish Council for Strategic Research (DSF) under the project: Danish Coasts and Climate Adaptation - Flooding risk and coastal protection (COADAPT), project no. 09-066869.

\section{References}

Drønen, N., Kristensen, S., Taaning, M., Elfrink, B., and Deigaard, R. (2011). Long term modeling of shoreline response to coastal structures. In The Proceedings of the Coastal Sediments, Miami, Florida. World Scientific.

Hansen, H. F., Deigaard, R., and Drønen, N. (2004). A numerical hybrid model for the morphology of a 
barred coast with a river mouth. In Smith, J. M., editor, Proceedings of the 29th International Conference on Coastal Engineering, pages 2607-2619, Lisbon, Portugal. World Scientific.

Harris, L. B. (1993). The seaport, table bay. an archaeological and historical perspective. ECU Research Report 8, East Carolina University.

Kærgaard, K. H. (2011). Numerical modeling of shoreline undulations. PhD thesis, Technical University of Denmark.

Kristensen, S., Deigaard, R., Taaning, M., Fredsøe, J., Drønen, N., and Jensen, J. (2010). Long term morphological modelling. In Smith, J. M. and Lynett, P., editors, Proceedings of the 32nd International Conference on Coastal Engineering, Shanghai, China. ASCE. 